\title{
Transsacrococcygeal approach in rectal gastrointestinal stromal tumour resection: 10-year experience at a single centre
}

\author{
Xiusen Qin ${ }^{1,2 \#}$, Chuangkun Li ${ }^{1,2 \#}$, Zifeng Yang ${ }^{1,2 \#}$, Wentai Guo ${ }^{1,2}$, Huili Guo ${ }^{2,3}$, Chun Chen ${ }^{1,2}$, \\ Rongkang Huang $^{1,2}$, Di Zhang ${ }^{1,2}$, Huaiming Wang ${ }^{1,2}$, Hui Wang ${ }^{1,2}$ \\ ${ }^{1}$ Department of Colorectal Surgery, The Sixth Affiliated Hospital, Sun Yat-sen University, Guangzhou, China; ${ }^{2}$ Guangdong Institute of \\ Gastroenterology, Guangdong Provincial Key Laboratory of Colorectal and Pelvic Floor Diseases, Supported by National Key Clinical Discipline, \\ The Sixth Affiliated Hospital, Sun Yat-sen University, Guangzhou, China; ${ }^{3}$ Department of Gastroenterology, The Sixth Affiliated Hospital, Sun Yat- \\ sen University, Guangzhou, China \\ Contributions: (I) Conception and design: H Wang, H Wang; (II) Administrative support: None; (III) Provision of study materials or patients: Z \\ Yang, H Wang; (IV) Collection and assembly of data: All authors; (V) Data analysis and interpretation: X Qin, C Li, Z Yang, W Guo, H Guo; (VI) \\ Manuscript writing: All authors; (VII) Final approval of manuscript: All authors. \\ \#These authors contributed equally to this work. \\ Correspondence to: Huaiming Wang; Hui Wang. Department of Colorectal Surgery, The Sixth Affiliated Hospital, Sun Yat-sen University, 26 Yuancun \\ Erheng Road, Guangzhou 510655, China. Email: wanghm7@mail.sysu.edu.cn; wang89@mail.sysu.edu.cn.
}

Background: The transsacrococcygeal (TSC) approach in rectal gastrointestinal stromal tumour (GIST) resection is clinically challenging and controversial, and we evaluated its value in the present study.

Methods: We enrolled patients who underwent rectal GIST resection by the TSC approach during 20082018. The clinicopathological index, surgical outcome, and prognosis were analysed. Prognostic information was obtained from medical records and follow-up data. Anal function was evaluated by the low anterior resection syndrome (LARS) score.

Results: Among 88 rectal GIST patients over the 10-year study period, 17 who underwent the TSC approach were analysed. The median age was 55 (range, 26-73) years. In total, 15 patients received preoperative imatinib neoadjuvant therapy for 232 (30-690) days. The tumours were exogenous in 14 patients and intramural in 3 patients. The mean initial tumour size and preoperative tumour size were $6.4 \pm 2.2$ and $4.2 \pm 1.7 \mathrm{~cm}$, respectively. The operative time and blood loss were $130.2 \pm 47.4 \mathrm{~min}$ and $44.6 \pm 36.0 \mathrm{~mL}$, respectively. Of the 17 patients 7 had postoperative complications (within 30 days postoperatively), and the complications of 5 patients were cured by conservative treatment. Only 1 patient was lost to follow-up, and the others had a good oncological prognosis at recent follow-up evaluations. All patients had LARS scores $\leq 9$ points at 1 year after the operation.

Conclusions: The TSC approach can result in a good oncological prognosis, usually does not affect anal function, and is particularly suitable for exogenous middle and low rectal GISTs. However, it might cause some controlled complications. Hence, careful patient selection is necessary for this operation.

Keywords: Rectal gastrointestinal stromal tumour (rectal GIST); transsacrococcygeal approach (TSC approach); prognosis; surgery; resection

Submitted Dec 09, 2020. Accepted for publication Jan 28, 2021.

doi: 10.21037/atm-20-8204

View this article at: http://dx.doi.org/10.21037/atm-20-8204 


\section{Introduction}

Gastrointestinal stromal tumours (GISTs) are the most common mesenchymal tumours in the gastrointestinal tract, occurring from the oesophagus to the anus and external gastrointestinal tract, with the stomach being the most common site (60\%), followed by the small intestine (30\%) (1). However, GISTs are rare in the rectum, accounting for no more than $5 \%$ of cases $(2,3)$. Due to the anatomical structure of the pelvic stenosis and the features of rectal GISTs, surgical management is very challenging $(4,5)$. Surgeons not only need to remove the tumour completely but also must protect anal function and the surrounding tissue.

Currently, the treatment of rectal GISTs is controversial, especially for middle and low rectal tumours (6-9). In the past, if local resection could not be completed, anterior rectal resection or the Miles procedure would be chosen. However, extensive resection leads to increased trauma and a high rate of postoperative complications, potentially leading to a long recovery and more pain for patients. Even so, the recurrence rate of rectal GISTs is still reported to be as high as $20-50 \%(10)$, which is related to the biological behaviour of the rectal GIST itself and the difficulty of surgical resection.

Due to the unique position and rarity of lymph node metastasis of rectal GISTs, it is possible to perform local resection by the transsacrococcygeal (TSC), transanal, transvaginal or transperineal approach. TSC approach is suitable for specific patients. It offers several advantages, including the possibility of obtaining better exposure, and of avoiding the risk of genitourinary and anal dysfunctions following total mesorectum excision (TME) $(11,12)$. In recent years, surgeons in The Sixth Affiliated Hospital have performed TSC resection for middle and low rectal GISTs, but this approach is rarely used in other institutions $(13,14)$. Therefore, we retrospectively evaluated rectal GISTs that were removed by the TSC approach in terms of clinical characteristics and outcomes and assessed the response to pre- and postoperative imatinib therapy. We present the following article in accordance with the STROBE reporting checklist (available at http://dx.doi.org/10.21037/atm-208204).

\section{Methods}

A retrospective analysis of rectal GIST cases was performed based on patients treated at The Sixth Affiliated
Hospital, Sun Yat-sen University from February 2008 to February 2018 (Figure 1). The enrolment criteria for this study were: (I) diagnosis with rectal GIST by two professional pathologists based on histopathology and immunohistochemical study; (II) complete clinicopathological data; (III) resection of rectal GIST by the TSC approach and (IV) postoperative follow-up for at least 1 year. The exclusion criteria were: (I) other serious diseases; (II) distant metastases at the time of surgery or presenting with other rectal tumours; and (III) death caused by other diseases. The primary outcomes were disease-free survival and anal function. The secondary outcome was the rate of complications.

All procedures performed in this study involving human participants were in accordance with the Declaration of Helsinki (as revised in 2013). This study was approved by the Research Ethics Committee of the Sixth Affiliated Hospital of Sun Yat-sen University, Guangzhou, China (2018ZSLYEC-099), and all patients provided informed consent for participation.

\section{Patients and clinical index}

The diagnostic information included the imaging and pathological findings. The following clinical data were collected and collated: age, sex, preoperative treatment, surgical and postoperative outcomes, and pathological outcomes. A core biopsy was used to confirm histology before treatment. All patients underwent computed tomography and magnetic resonance imaging (MRI) examinations before operation, and the tumour size was obtained from high-resolution MRI. The modified National Institutes of Health (NIH) risk system was used to assess the risk of recurrence. Tumour response evaluation was assessed by RECIST 1.1 (15).

\section{Surgical procedures}

The main surgical approach was based on the technique originally described by Canessa (16). We modified the procedure (Figure 2), taking the resection of an anterior wall rectal GIST as an example. (I) The approach is performed in the prone jack-knife position. The rectal mass is examined with a finger through the anus; an anterior wall tumour might also be examined through the vagina. Next, a midline skin incision is made from the level of the sacrococcygeal joint (SCJ) to the anal edge, and an incision is made halfway around the anus according to the tumour's 


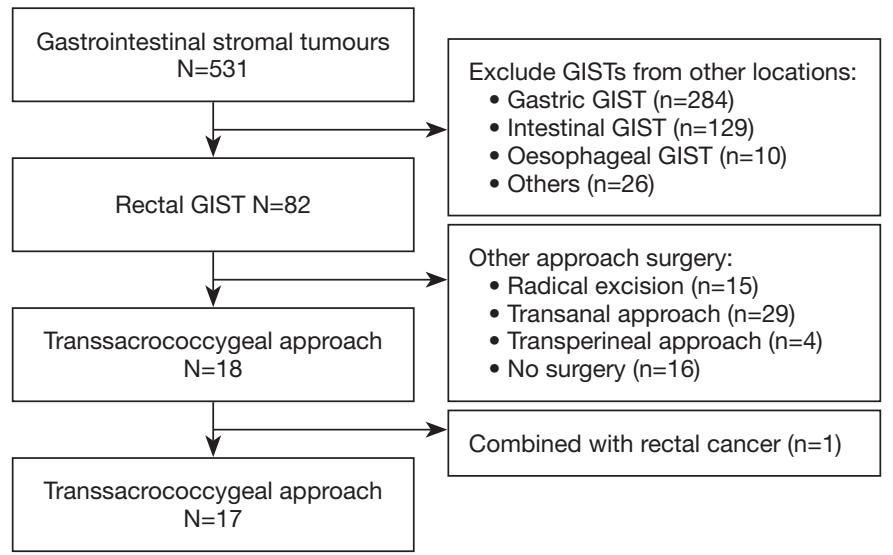

Figure 1 Study flowchart. Rectal GISTs resected by the TSC approach in the Sixth Affiliated Hospital, Sun Yat-sen University from February 2008 to February 2018. GIST, gastrointestinal stromal tumour; TSC, transsacrococcygeal.
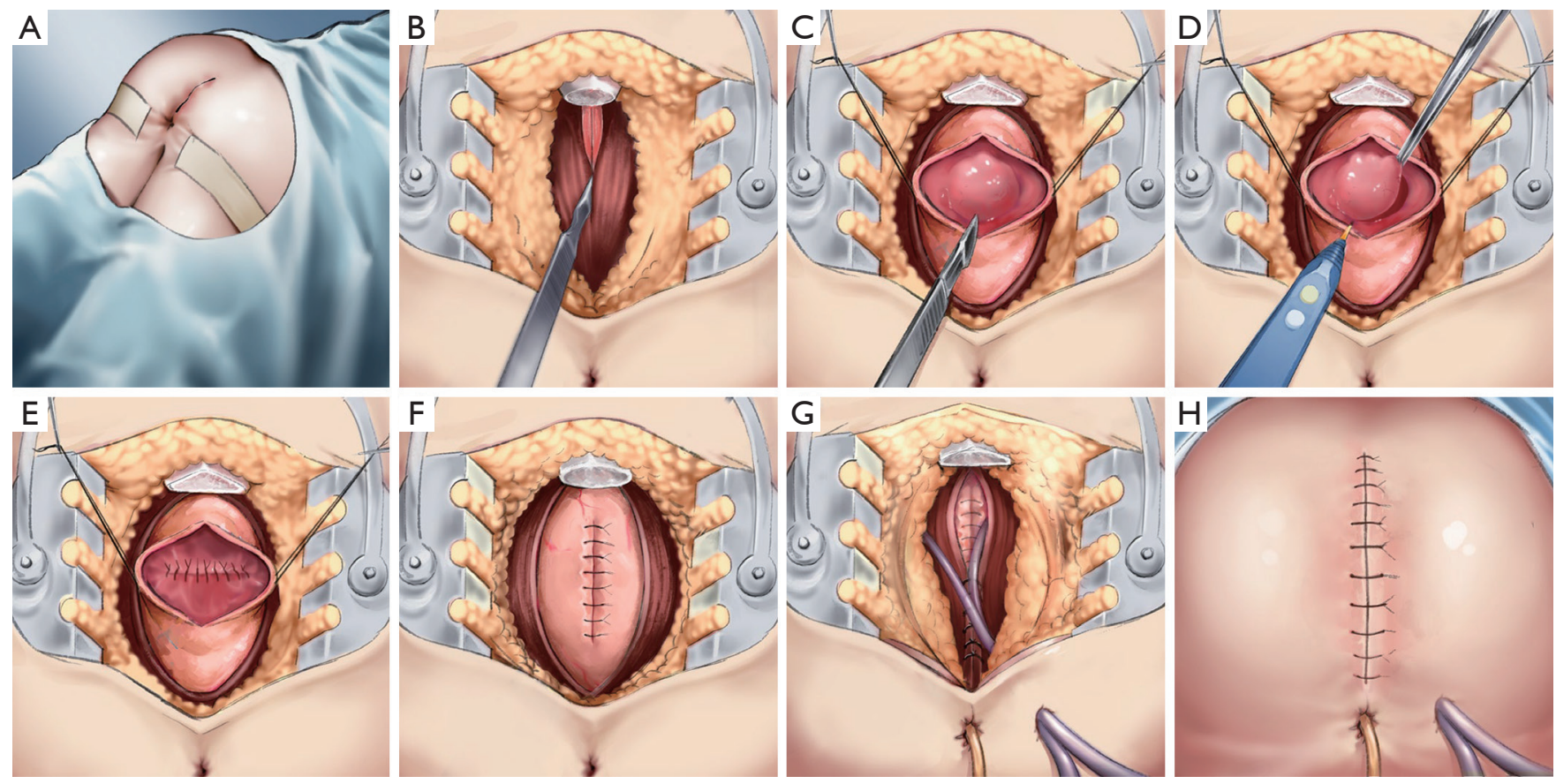

Figure 2 Surgical technique for transsacrococcygeal approach to resect of rectal gastrointestinal stromal tumour. (A) Operative position and surgical incision; (B) freeing and removal of the coccyx and exposure of the posterior wall of the rectum; (C) proctotomy and exposure of the tumour located in the anterior wall of the rectum; (D) removal of the tumour; (E) suturing the anterior wall of the rectum; (F) suturing the posterior wall of the rectum; $(\mathrm{G})$ drainage tube placed and tissues closed in layers; and $(\mathrm{H})$ skin incision closed.

location to expose the SCJ. (II) If the tumour is located at the middle of the rectum, the coccyx is freed and removed. The pelvic subperitoneal space is enlarged, and the posterior wall of the rectum exposed. (III) A proctotomy is performed and then the tumour located in the anterior wall of the rectum is exposed. (IV) The tumour is removed and the anterior wall of the rectum sutured. (V) The posterior wall of the rectum is sutured. (VI) A drainage tube is placed, and the tissues closed in layers. At the deepest part of the wound, one silicone drainage tube is placed next to the mesorectum and the posterior rectal space, and an anal tube is placed through the anus (VII) The skin incision is closed. 
Table 1 Clinical information of rectal GIST patients

\begin{tabular}{lc}
\hline Clinical information & $N(\%) /$ mean \pm SD \\
\hline Median age [years] & $55[26-73]$ \\
$>60$ & $8(47.0 \%)$ \\
$\leq 60$ & $9(53.0 \%)$ \\
Sex & \\
Male & $11(64.7 \%)$ \\
Female & $6(35.3 \%)$ \\
Presenting symptom & \\
Yes & $15(88.2 \%)$ \\
No & $2(11.8 \%)$ \\
Biopsy & \\
Yes & $15(88.2 \%)$ \\
No & $2(11.8 \%)$ \\
Neoadjuvant therapy & \\
Yes & $15(88.2 \%)$ \\
No & $2(11.8 \%)$ \\
Neoadjuvant therapy (days) & $232.0 \pm 174.7$ \\
\hline
\end{tabular}

GIST, gastrointestinal stromal tumour; SD, standard deviation.

\section{Follow-up information}

Follow-up was carried out over the telephone or by a medical history review. The follow-up data included postoperative adjuvant therapy, survival information, and the low anterior resection syndrome (LARS) score. The LARS score was retrospectively evaluated by the LARS Scoring Instructions (17). Follow-up time was defined as the period from the first day of discharge to the date of the interview, and survival time was defined as the period from the first day of discharge to the date of the interview or the date of death. High-resolution MRI was used to evaluate whether the tumour had recurred.

\section{Statistical analysis}

All data are described as the mean \pm standard deviation or $\mathrm{n}(\%)$. Statistical analyses were performed using SPSS version 25.0 (SPSS, Chicago, IL, USA), and survival curves were generated using GraphPad Prism 8.0 (San Diego, CA, USA). One patient who was lost to follow-up was also included in the study

\section{Results}

\section{Case descriptions}

Of a total of 531 GIST patients from the Sixth Affiliated Hospital of Sun Yat-sen University identified between 2008 and 2018, 18 with rectal GISTs underwent TSC resection. Of them, 17 patients with rectal GISTs were eligible and one patient who also had rectal cancer was excluded.for this study (Figure 1). The median age was 55 (range, 2673) years, and 8 patients (47.3\%) were older than 60 years (Table 1). There were no obvious clinical symptoms in $11.8 \%$ of the patients, in whom the tumour was found by digital rectal examination; the remaining $88.2 \%$ of patients demonstrated symptoms of anal bulge ( 5 cases), constipation (5 cases), haematochezia (2 cases), anal masses (2 cases) and perianal discomfort (1 case). Of the 17 patients, 2 had experienced recurrence after surgery in other hospitals and were then transferred for further treatment. The initial tumour size ranged from 4 to $12 \mathrm{~cm}$, with an average diameter of $6.4 \mathrm{~cm}$. Pathological evidence was found in all 15 patients before imatinib therapy. The representative images of MRI before and after neoadjuvant imatinib therapy can be seen in Figure 3. The distance from the tumour to the anal verge was within $5.5 \mathrm{~cm}$. Among the 15 patients treated with imatinib, 10 achieved a partial response, 3 had stable disease and 2 had progressive disease. Two patients underwent surgery directly after a definite diagnosis; their tumour sizes were 4 and $5 \mathrm{~cm}$, and the distances from the anal margin were 5 and $3.1 \mathrm{~cm}$, respectively (Table 2).

\section{Pathological outcomes}

All 17 patients underwent pathological examination after the operation. The final pathological diagnosis was made according to histological morphology and immunohistochemical staining of the specimens. The tumours were exogenous in 14 patients and intramural in 3 patients. The mitotic counts were $\leq 5 / 50,(5-10) / 50$, and $\geq 10 / 50$ per high-power field in $11(64.7 \%), 6(35.3 \%)$, and $0(0 \%)$ patients, respectively. Immunohistochemistry demonstrated that 17 (100\%), 16 (94.1\%), and 13 (76.5\%) of the patients had expression of $\mathrm{CD} 34^{+}, \mathrm{CD} 117^{+}$, and DOG $-1^{+}$, respectively. According to the modified NIH risk classification system, 1 patient (5.9\%), 4 patients (23.5\%), 1 patient $(5.9 \%)$ and 11 patients $(64.7 \%)$ were in the categories of very low risk, low risk, intermediate risk and 

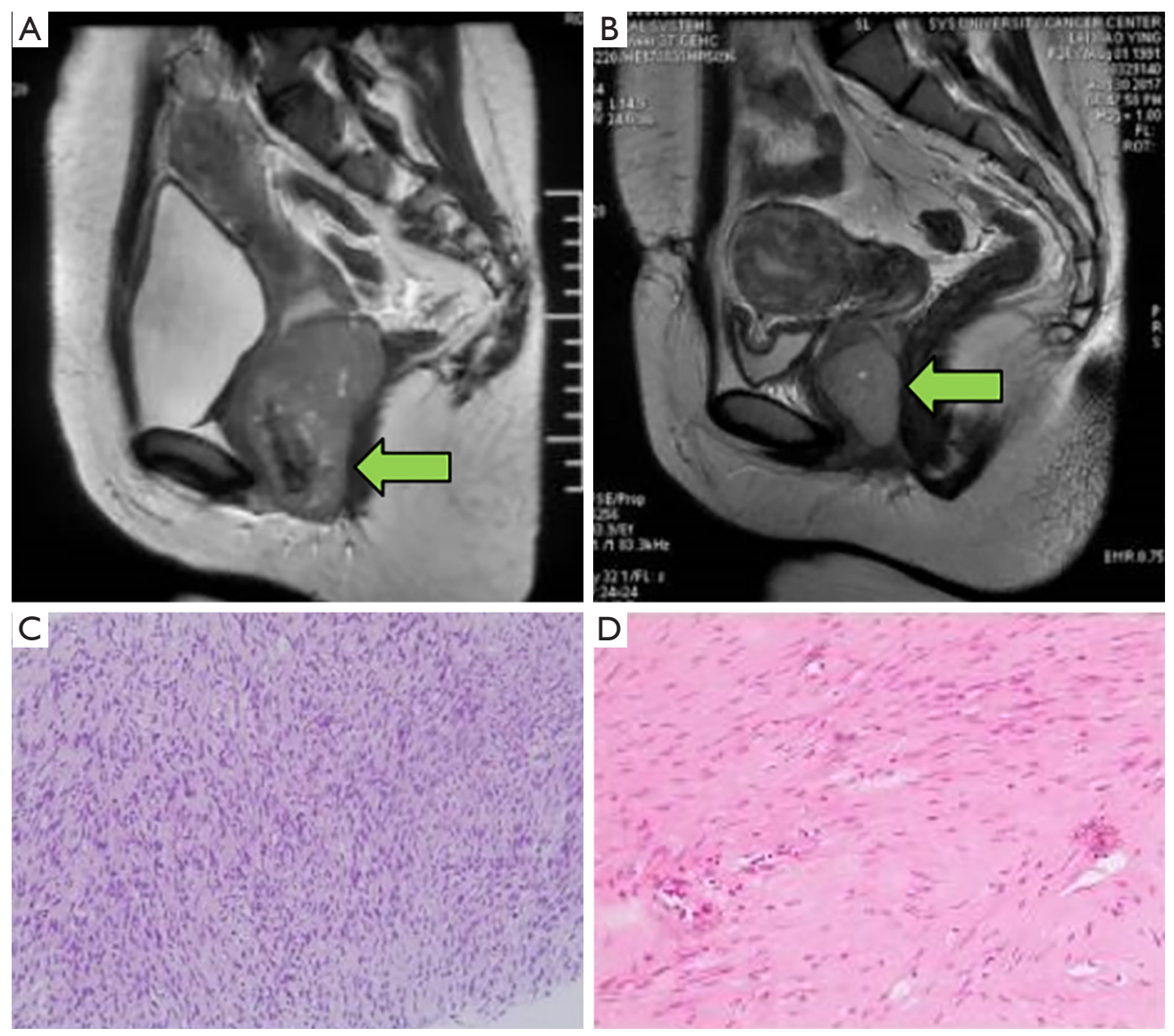

Figure 3 Comparison of magnetic resonance imaging (MRI) and pathological images pre- and post-neoadjuvant imatinib in a patient with anterior rectal gastrointestinal stromal tumour (GIST) (The “ $\longleftarrow$ ” points to the location of tumour). (A) Anterior rectal GIST before imatinib (maximum tumour diameter $8.2 \mathrm{~cm}$ ) and (B) at 10 months after imatinib treatment (maximum tumour diameter $5.0 \mathrm{~cm})$. (C) The pathological image prior to neoadjuvant therapy showing tumour spindle cells $(\mathrm{H} \& \mathrm{E}, \times 100)$. (D) The pathological image after imatinib therapy $(\mathrm{H} \& \mathrm{E}, \times 200)$.

high risk, respectively (Table 2).

\section{Surgical outcomes}

All patients underwent TSC resection of rectal GISTs, and imatinib was discontinued 2 weeks before surgery. The mean operation time, blood loss and postoperative hospitalisation stay were $130.2 \pm 47.4 \mathrm{~min}, 44.6 \pm 36.0 \mathrm{~mL}$, and $25.4 \pm 14.3$ days, respectively (Table 3 ). All patients had a negative surgical margin, and 1 patient experienced tumour rupture during the operation. Two patients underwent prophylactic ileostomy. Postoperative complications (within 30 days postoperative) occurred in 7 patients (41.2\%) and included 5 cases of leakage and 2 cases of poor wound healing. Among the 5 cases of leakage, 4 patients had rectal leakage, and 1 had a rectovaginal fistula. Case 1 and Case 3 with rectal leakage recovered after conservative treatment, including unobtrusive drainage and irrigation, but the hospital stay was relatively long, and Case 2 underwent sigmoidostomy (Table 4). In Case 4, the tumour had invaded the posterior wall of the vagina, which was partially excised and repaired by a gynaecologist. This patient had a rectovaginal fistula after surgery and underwent colostomy, which could not be closed after several months because of existing leakage. In Case 7, postoperative sacrococcygeal incision debridement was performed 7 days after surgery, and ileostomy was performed 12 days after surgery. After 5 months, anal stenosis was found, and it was not possible to close the stoma. Anal dilation was treated, and the stoma was closed 15 months later. 
Table 2 Pathological outcomes

\begin{tabular}{|c|c|}
\hline Pathological outcomes & $\mathrm{N}(\%) /$ mean $\pm \mathrm{SD}$ \\
\hline \multicolumn{2}{|l|}{ Tumour location } \\
\hline Anterior & $6(35.3 \%)$ \\
\hline Posterior & $2(11.8 \%)$ \\
\hline Lateral & $9(52.9 \%)$ \\
\hline \multicolumn{2}{|l|}{ Pattern of tumour growth } \\
\hline Endogenous & 0 \\
\hline Intramural & $3(17.6 \%)$ \\
\hline Exogenous & $14(82.4 \%)$ \\
\hline Distance from anal verge $(\mathrm{cm})$ & $3.3 \pm 1.4$ \\
\hline Initial tumour diameter (cm) & $6.4 \pm 2.2$ \\
\hline \multicolumn{2}{|c|}{ Tumour size (cm, before neoadjuvant therapy) } \\
\hline$<2$ & $1(5.9 \%)$ \\
\hline $2-5$ & $11(64.7 \%)$ \\
\hline $5.1-9.9$ & $5(29.4 \%)$ \\
\hline Preoperative tumour diameter (cm) & $4.2 \pm 1.7$ \\
\hline \multicolumn{2}{|l|}{ Response evaluation } \\
\hline Complete response (CR) & 0 \\
\hline Partial response (PR) & $10(66.7 \%)$ \\
\hline Stable disease (SD) & $3(20 \%)$ \\
\hline Progressive disease (PD) & $2(13.3 \%)$ \\
\hline \multicolumn{2}{|l|}{ Mitotic count (/50 HPF) } \\
\hline$\leq 5$ & $11(64.7 \%)$ \\
\hline $5-10$ & $6(35.3 \%)$ \\
\hline \multicolumn{2}{|l|}{$\mathrm{IHC}$} \\
\hline $\mathrm{CD}^{+} 4^{+}$ & $17(100 \%)$ \\
\hline $\mathrm{CD} 117^{+}$ & $16(94.1 \%)$ \\
\hline $\operatorname{Dog}-1^{+}$ & $13(76.5 \%)$ \\
\hline \multicolumn{2}{|l|}{ Tumour rupture } \\
\hline Yes & $1(5.9 \%)$ \\
\hline \multicolumn{2}{|l|}{ Surgical margin } \\
\hline Positive & 0 \\
\hline \multicolumn{2}{|l|}{ NIH criteria } \\
\hline Very low & $1(5.9 \%)$ \\
\hline Low & 4 (23.5\%) \\
\hline Intermediate & $1(5.9 \%)$ \\
\hline High & $11(64.7 \%)$ \\
\hline
\end{tabular}

Response evaluation was assessed by RECIST 1.1; HPF, high-power field; IHC, immuno-histochemistry; NIH, National Institutes of Health. SD, standard deviation
Table 3 Surgical outcomes

\begin{tabular}{lc}
\hline Surgical outcomes & $\mathrm{N}(\%) /$ mean $\pm \mathrm{SD}$ \\
\hline Operative time (min) & $130.2 \pm 47.4$ \\
Blood loss $(\mathrm{mL})$ & $44.6 \pm 36.0$ \\
Postoperative hospitalisation (days) & $25.4 \pm 14.3$ \\
Complications & \\
Leakage & $5(29.4 \%)$ \\
Poor wound healing & $2(11.8 \%)$ \\
\hline
\end{tabular}

$\mathrm{SD}$, standard deviation.

\section{Postoperative therapy and survival information}

After the operation, 14 patients received imatinib treatment, which lasted more than 1 year (1-8 years). Of the 17 patients, 1 was lost to follow-up, but the others survived to the most recent follow-up evaluation. Patients were followed up for a range of 17-99 months, with a median of 52 months (Table 5). There was 1 case of recurrence 1 month after surgery. Subsequently, the tumour was treated with imatinib for 6 months, but did not shrink, so the patient underwent resection by the TSC approach again, and postoperative treatment with imatinib has been performed to date. All patients had a good survival prognosis (Figure 4). All patients had a LARS score $\leq 9$ points at 1 year after the operation, and none had anal dysfunction (Table 6).

\section{Discussion}

In this study, patients had a good oncological prognosis and anal function, and the postoperative results were consistent with previous reports $(11,12)$, although the complication rate does seem high.

Due to their low incidence and limited clinical studies, the treatment of rectal GISTs is still controversial. Surgical resection is the main treatment method $(18,19)$, including local resection and radical excision. Local resection includes transanal, transperineal, and TSC approaches. Radical excision mainly consists of lower anterior resection and the Miles procedure, and will cause increased trauma and the loss of some physiological functions. In this study, 19.3\% of patients with rectal GISTs underwent TSC resection, a proportion that was higher than in Jakob et al.'s (1/38) (14) and Wilkinson et al.'s (0/13) (13) reports. The high proportion may be explained by the fact that our centre is the largest gastrointestinal specialist hospital in China, 
Table 4 Complications within 30 days after surgery

\begin{tabular}{|c|c|c|c|c|c|c|c|c|c|}
\hline $\begin{array}{l}\text { Case } \\
\text { no. }\end{array}$ & $\begin{array}{l}\text { Date of } \\
\text { surgery }\end{array}$ & $\begin{array}{c}\text { Age } \\
\text { interval }^{\mathrm{a}}\end{array}$ & $\begin{array}{l}\text { Tumour } \\
\text { location }\end{array}$ & $\begin{array}{l}\text { Distance from } \\
\text { anus }(\mathrm{cm})\end{array}$ & $\begin{array}{l}\text { Tumour } \\
\text { size }(\mathrm{cm})\end{array}$ & Complication & Treatment & Outcome & $\begin{array}{l}\text { Hospital-isation } \\
\text { (days) }\end{array}$ \\
\hline 1 & 2016.1 & $70-75$ & Lateral & 2.8 & 3.5 & Leakage & Drainage & Recovered & 24 \\
\hline 3 & 2013.9 & $70-73$ & Anterior & 3.1 & 5.0 & $\begin{array}{c}\text { Sacrococcygeal } \\
\text { sinus tract }\end{array}$ & Drainage & Recovered & 48 \\
\hline 4 & 2013.12 & $55-60$ & Anterior & 2.5 & 6.1 & Rectovaginal fistula & Sigmoidostomy & $\begin{array}{l}\text { Rectostenosis and } \\
\text { permanent stoma }\end{array}$ & 30 \\
\hline 5 & 2017.11 & $60-65$ & Posterior & 5 & 6.5 & $\begin{array}{l}\text { Poor wound healing } \\
\text { of the rectum }\end{array}$ & $\begin{array}{l}\text { Conservative } \\
\text { treatment }\end{array}$ & Recovered & 56 \\
\hline 6 & 2014.7 & $65-70$ & Lateral & 2.6 & 2.0 & $\begin{array}{c}\text { Wound dehiscence } \\
\text { of the skin }\end{array}$ & $\begin{array}{l}\text { Conservative } \\
\text { treatment }\end{array}$ & Recovered & 23 \\
\hline
\end{tabular}

${ }^{\mathrm{a}}$, ages are presented as a range in order to avoid indirectly identifying patient data.

Table 5 Postoperative therapy and follow-up

\begin{tabular}{lc}
\hline Postoperative therapy and prognosis & $N(\%) /$ mean \pm SD \\
\hline Postoperative adjuvant therapy & $14(82.4 \%)$ \\
Yes & $3(17.6 \%)$ \\
No & \\
Recurrence & $1(5.9 \%)$ \\
Yes & $15(88.2 \%)$ \\
No & $1(5.9 \%)$ \\
Lost to follow-up & 52 \\
Median follow-up (months) & 55 \\
Median survival time (months) & $100(100 \%)$ \\
LARS score & 0 \\
$\leq 9$ & \\
$>9$ &
\end{tabular}

LARS, low anterior resection syndrome.

and surgeons have extensive experience; therefore, more difficult patients are sent here for treatment.

The posterior approach has been reported to have low morbidity and good oncological outcomes $(20,21)$, but the TSC approach is still controversial because of complications such as leakage, wound infection and poor wound healing. Other debated factors include surgical indication, the procedures, and operability. In our centre, the average operation time was $130.2 \pm 47.4 \mathrm{~min}$, which indirectly reflects the feasibility of surgery. In this study, 7 of the 17 patients had different degrees of complications, including 5 cases of leakage and 2 cases of poor wound healing. The high incidence rate of complications may be attributed to the specific location of the tumour, the ages of the patients, experience of the surgeon, and the complexity of the cases. Of the 7 patients with complications 6 had a rectal GIST located at the lateral or anterior wall of the rectum. Case 1 and Case 6 in this study underwent a second tumour excision operation due to recurrence, and a second operation may increase the difficulty of the operation. In addition, the average age and blood loss of patients with complications (58.6 years and $51.4 \mathrm{~mL}$, respectively) were higher than those of patients without complications (54.0 years and $39.3 \mathrm{~mL}$, respectively). Complications also lead to postoperative hospitalisation. Fortunately, all patients obtained a good survival prognosis. Therefore, methods to reduce the incidence of complications should be examined. To reduce the incidence of leakage, a leak test with methylene blue or water is important to ensure the absence of leak. Optimisation of suture techniques, prophylactic ileostomy and postoperative nursing could reduce the incidence of leakage and other serious complications.

The standard treatment for resectable rectal GIST is complete surgical resection without dissection of clinically negative lymph nodes (7). Pre-treatment with imatinib 

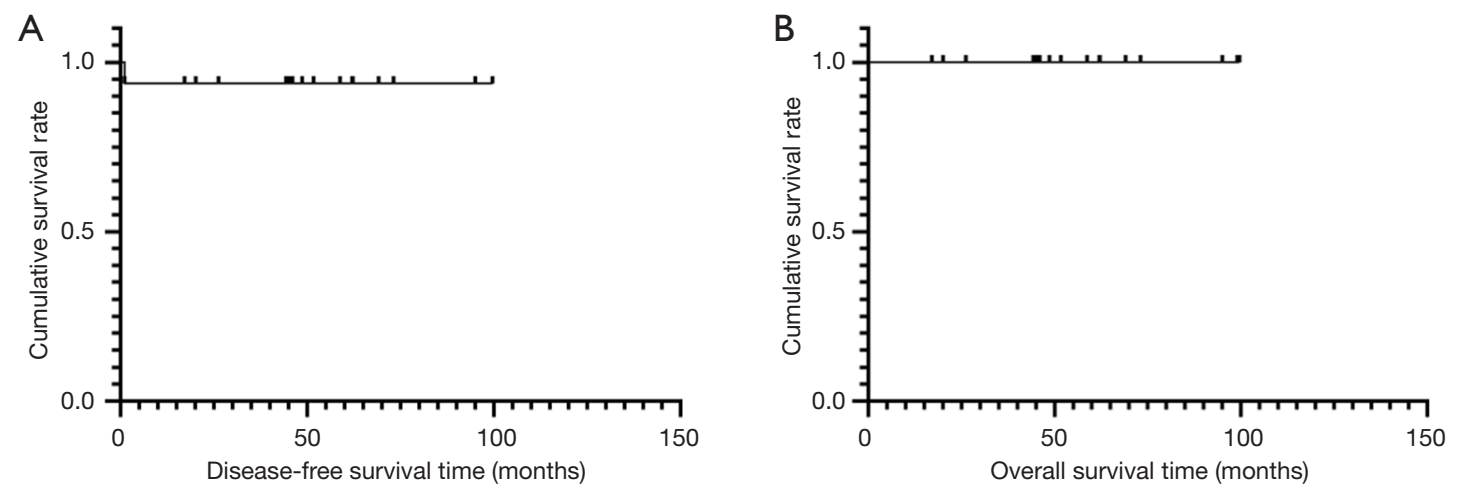

Figure 4 (A) Disease-free survival curve and (B) overall survival curve of the 17 rectal gastrointestinal stromal tumour (GIST) patients.

Table 6 LARS score at 1 year after surgery

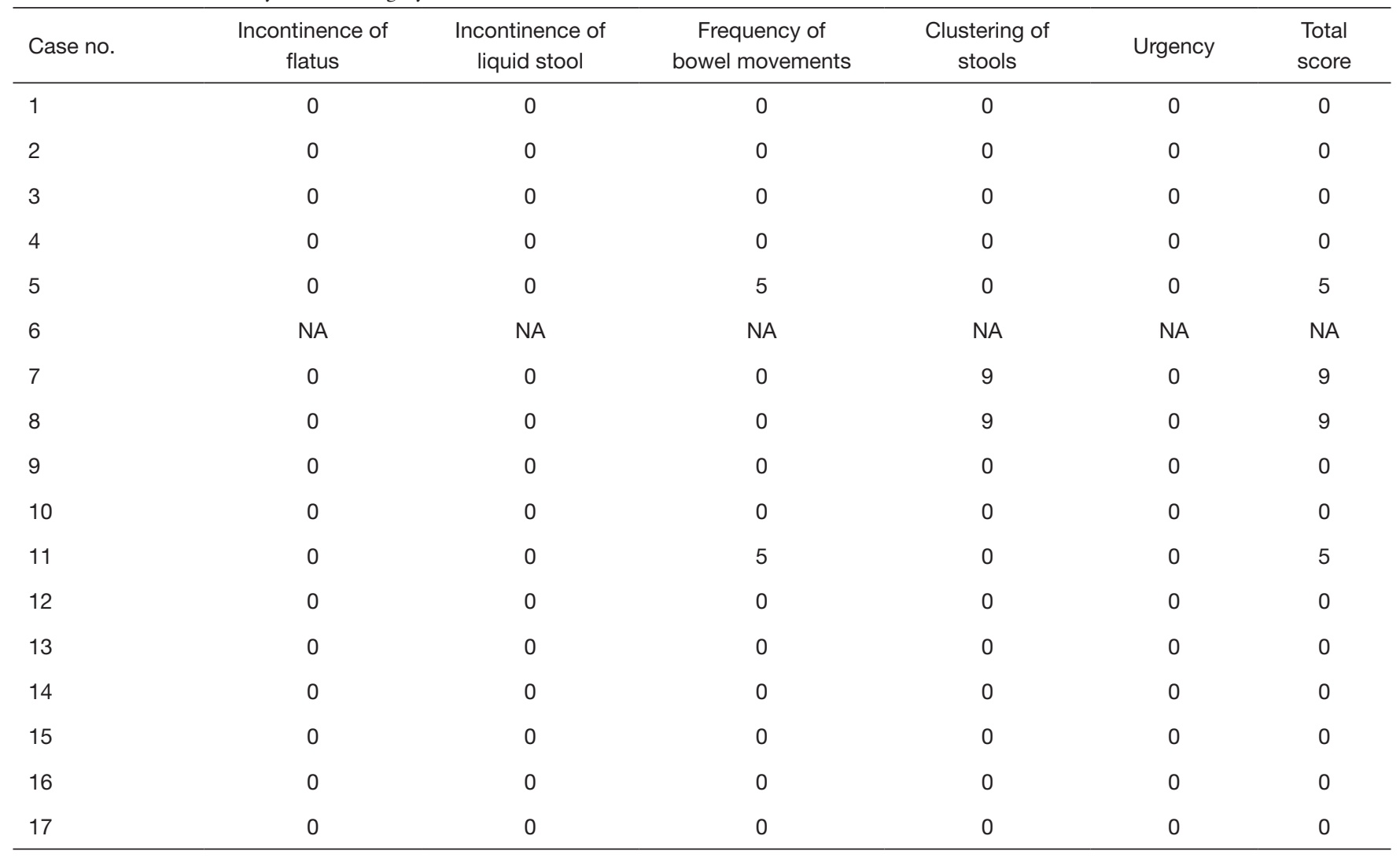

Interpretation: 0-20: no LARS; 21-29: minor LARS; 30-42: major LARS. LARS, low anterior resection syndrome; NA, not applicable. Patient of Case 6 had a permanent ostomy.

should be considered if $\mathrm{R} 0$ resection is not feasible, or it can be achieved by less invasive/functionally preserving surgery in the case of reduced tumour size. For unresectable or metastatic rectal GISTs, imatinib is the primary therapy; Surgery may be indicated for limited disease progression, previously unresectable tumours after a favorable response to preoperative imatinib or symptomatic bleeding or obstruction (6).

In terms of the surgical approach, transanal resection is more minimally invasive for rectal GIST treatment, but it 
is difficult to visualise a complete exogenous rectal tumour. In recent years, transanal endoscopic microsurgery has been performed; this operation can remove tumours with a full layer of the rectum (22) and offers access to high lesions, but special instruments and technical experience are required (23). For an exogenous tumour, the TSC approach is conducive to exposing the tumour completely, identifying nerves and muscles, and protecting anal function, especially for tumours located at the posterolateral wall of the middle and lower rectum. On the other hand, Gervaz et al. reported that rectal GISTs are generally not associated with lymph node metastasis and are more suitable for TSC resection (11). Compared with radical excision, this approach is less traumatic and helps maintain sexual and anal functions (21). In this study, $82.4 \%$ of the cases had exogenous tumours, and the distance from the lower edge of the tumour to the anal edge was within $5 \mathrm{~cm}$.

However, the indications for resection of rectal GISTs by the TSC approach still need to be mastered, and tumour size, location, and surrounding invasion need to be comprehensively considered. Because the size of the tumour is closely related to the risk of recurrence and the choice of surgical approach (24), local resection is feasible for most patients with small tumours (diameter $<5 \mathrm{~cm}$ ) (25). For tumours in the lower rectum, transanal resection is safe and feasible as long as a safe cutting margin of $1 \mathrm{~cm}$ can be guaranteed. For women with tumours in the middle of the anterior wall of the rectum, transvaginal resection may be considered. For tumours located in the posterior wall of the middle segment of the rectum, especially tumours growing away from the rectal lumen, the TSC approach is the best choice. For stromal tumours in the upper segment of the rectum, transabdominal tumour resection is suitable. According to our data, the sum of the preoperative tumour diameter and the distance from the tumour to the anal verge ranged from 3.6 to $11 \mathrm{~cm}$, and there were 6,2 and 9 cases located in the anterior, posterior and lateral walls of the rectum, respectively. This suggests that the TSC approach is more appropriate when the tumour is located at the middle and lower rectum. It is worth mentioning that the presence of a tumour in the anterior wall of the rectum is not a contraindication to this procedure. We recommend the TSC approach for resection of intramural or exogenous rectal GISTs in the middle and lower rectum. Since this approach is rarely used, it should be carried out in centres with rich professional experience based on individualized treatment.

In addition, for patients diagnosed with rectal GIST, imatinib neoadjuvant therapy is feasible, and surgery can be performed when the tumour cannot shrink further. The incidence of rectal stromal tumours is low, and the degree of risk is usually high. Neoadjuvant imatinib therapy for rectal GISTs offers a number of potential benefits (26), including tumour downsizing, reduction in mitotic activity, reduced morbidity, and a reduced risk of recurrence (27) Patients with intermediate or high risk should continue to use imatinib $400 \mathrm{mg} /$ day as adjunctive therapy after surgery for at least 3 years. In this study, differences were noted in tumour diameter between before and after treatment with imatinib, which significantly reduced the mean tumour size from $6.4(2.6-8.6)$ to $4.2(2.0-6.8) \mathrm{cm}$ (95\% confidence interval, $\mathrm{P}<0.05)$.

Given the long latency period between the primary surgical intervention and recurrence and/or metastasis, regular follow-up at 3-6-month intervals in the first 3 postoperative years is highly recommended, especially for patients with intermediate and high-risk rectal GISTs. Close surveillance also allows for the early discovery of local recurrence after local excision. Case 1 and Case 6 in this study underwent surgery at local hospitals and then re-presented to us due to recurrence. To date, they have exhibited recurrence-free survival after the second surgery.

Finally, the study was limited by its small sample size and retrospective design, but this technique is an alternative to consider in selected cases of rectal tumours.

\section{Conclusions}

Currently, there are few reports on the TSC approach to resect rectal GISTs. Our study suggests that this operation can achieve a good oncological prognosis, usually does not affect anal function, and is particularly suitable for exogenous middle and low rectal GISTs. However, it can also cause some controlled complications. Hence, careful patient selection and an experienced surgeon are necessary for this operation.

\section{Acknowledgments}

The authors thank Tianzuo Niu for the valuable data collection.

Funding: This work was supported by the Guangzhou Science and Technology Project (201704020059).

\section{Footnote}

Reporting Checklist: The authors have completed the 
STROBE reporting checklist. Available at http://dx.doi. org/10.21037/atm-20-8204

Data Sharing Statement: Available at http://dx.doi. org/10.21037/atm-20-8204

Conflicts of Interest: All authors have completed the ICMJE uniform disclosure form (available at http://dx.doi. org/10.21037/atm-20-8204). The authors have no conflicts of interest to declare.

Ethical Statement: The authors are accountable for all aspects of the work in ensuring that questions related to the accuracy or integrity of any part of the work are appropriately investigated and resolved. All procedures performed in this study involving human participants were in accordance with the Declaration of Helsinki (as revised in 2013). This study was approved by the Research Ethics Committee of the Sixth Affiliated Hospital of Sun Yat-sen University, Guangzhou, China (No. 2018ZSLYEC-099), and all patients provided informed consent for participation.

Open Access Statement: This is an Open Access article distributed in accordance with the Creative Commons Attribution-NonCommercial-NoDerivs 4.0 International License (CC BY-NC-ND 4.0), which permits the noncommercial replication and distribution of the article with the strict proviso that no changes or edits are made and the original work is properly cited (including links to both the formal publication through the relevant DOI and the license). See: https://creativecommons.org/licenses/by-nc-nd/4.0/.

\section{References}

1. Miettinen M, Sarlomo-Rikala M, Lasota J. Gastrointestinal stromal tumors: recent advances in understanding of their biology. Hum Pathol 1999;30:1213-20.

2. Miettinen M, Lasota J. Gastrointestinal stromal tumors-definition, clinical, histological, immunohistochemical, and molecular genetic features and differential diagnosis. Virchows Arch 2001;438:1-12.

3. Tran T, Davila JA, El-Serag HB. The epidemiology of malignant gastrointestinal stromal tumors: an analysis of 1,458 cases from 1992 to 2000 . Am J Gastroenterol 2005;100:162-8.

4. Tielen R, Verhoef C, van Coevorden F, et al. Surgical management of rectal gastrointestinal stromal tumors. J Surg Oncol 2013;107:320-3.
5. Changchien CR, Wu MC, Tasi WS, et al. Evaluation of prognosis for malignant rectal gastrointestinal stromal tumor by clinical parameters and immunohistochemical staining. Dis Colon Rectum 2004;47:1922-9.

6. von Mehren M, Randall RL, Benjamin RS, et al. Soft Tissue Sarcoma, Version 2.2018, NCCN Clinical Practice Guidelines in Oncology. J Natl Compr Canc Netw 2018;16:536-63.

7. Casali PG, Abecassis N, Aro HT, et al. Gastrointestinal stromal tumours: ESMO-EURACAN Clinical Practice Guidelines for diagnosis, treatment and follow-up. Ann Oncol 2018;29:iv68-iv78.

8. Kameyama H, Kanda T, Tajima Y, et al. Management of rectal gastrointestinal stromal tumor. Transl Gastroenterol Hepatol 2018;3:8.

9. Kane WJ, Friel CM. Diagnosis and Treatment of Rectal Gastrointestinal Stromal Tumors. Dis Colon Rectum 2019;62:537-40.

10. Agaimy A, Vassos N, Markl B, et al. Anorectal gastrointestinal stromal tumors: a retrospective multicenter analysis of 15 cases emphasizing their high local recurrence rate and the need for standardized therapeutic approach. Int J Colorectal Dis 2013;28:1057-64.

11. Gervaz P, Huber O, Bucher P, et al. Trans-sacral (Kraske) approach for gastrointestinal stromal tumour of the lower rectum: old procedure for a new disease. Colorectal Dis 2008;10:951-2.

12. Matsushima K, Kayo M. Transsacral approach to resect a gastrointestinal stromal tumor in the rectum: report of two cases. Surg Today 2007;37:698-701.

13. Wilkinson MJ, Fitzgerald JE, Strauss DC, et al. Surgical treatment of gastrointestinal stromal tumour of the rectum in the era of imatinib. Br J Surg 2015;102:965-71.

14. Jakob J, Mussi C, Ronellenfitsch U, et al. Gastrointestinal stromal tumor of the rectum: results of surgical and multimodality therapy in the era of imatinib. Ann Surg Oncol 2013;20:586-92.

15. Eisenhauer EA, Therasse P, Bogaerts J, et al. New response evaluation criteria in solid tumours: revised RECIST guideline (version 1.1). Eur J Cancer 2009;45:228-47.

16. Canessa CE. Dorsal transsacrococcygeal rectal approach. Dis Colon Rectum 2005;48:1663-5.

17. Emmertsen KJ, Laurberg S. Low anterior resection syndrome score: development and validation of a symptom-based scoring system for bowel dysfunction after low anterior resection for rectal cancer. Ann Surg 2012;255:922-8.

18. Logrono R, Jones DV, Faruqi S, et al. Recent advances 
in cell biology, diagnosis, and therapy of gastrointestinal stromal tumor (GIST). Cancer Biol Ther 2004;3:251-8.

19. Gervaz P, Huber O, Morel P. Surgical management of gastrointestinal stromal tumours. Br J Surg 2009;96:567-78.

20. Chereau N, Lefevre JH, Meurette G, et al. Surgical resection of retrorectal tumours in adults: long-term results in 47 patients. Colorectal Dis 2013;15:e476-82.

21. Aranda-Narvaez JM, Gonzalez-Sanchez AJ, MontielCasado C, et al. Posterior approach (Kraske procedure) for surgical treatment of presacral tumors. World J Gastrointest Surg 2012;4:126-30.

22. Althumairi AA, Gearhart SL. Local excision for early rectal cancer: transanal endoscopic microsurgery and beyond. J Gastrointest Oncol 2015;6:296-306.

23. Buess G, Mentges B, Manncke K, et al. Technique and results of transanal endoscopic microsurgery in early rectal

Cite this article as: Qin X, Li C, Yang Z, Guo W, Guo H, Chen C, Huang R, Zhang D, Wang H, Wang H. Transsacrococcygeal approach in rectal gastrointestinal stromal tumour resection: 10-year experience at a single centre. Ann Transl Med 2021;9(4):341. doi: 10.21037/atm-20-8204 cancer. Am J Surg 1992;163:63-9; discussion 9-70.

24. Hawkins AT, Wells KO, Krishnamurty DM, et al. Preoperative Chemotherapy and Survival for Large Anorectal Gastrointestinal Stromal Tumors: A National Analysis of 333 Cases. Ann Surg Oncol 2017;24:1195-201.

25. Liu H, Yan Z, Liao G, et al. Treatment strategy of rectal gastrointestinal stromal tumor (GIST). J Surg Oncol 2014;109:708-13.

26. Cavnar MJ, Wang L, Balachandran VP, et al. Rectal Gastrointestinal Stromal Tumor (GIST) in the Era of Imatinib: Organ Preservation and Improved Oncologic Outcome. Ann Surg Oncol 2017;24:3972-80.

27. Kaneko M, Emoto S, Murono K, et al. Neoadjuvant imatinib therapy in rectal gastrointestinal stromal tumors. Surg Today 2019;49:460-6.

(English Language Editor: K. Brown) 